\title{
The Scope and Aims of Human Geography.*
}

\author{
By Prof. P. M. Roxby.
}

$\mathbf{I}^{\mathrm{T}}$ $\mathrm{T}$ is to Ritter and Humboldt that we owe the real beginnings of human geography as an integral and, indeed, from Ritter's point of view, the crowning part of the subject matter. To appreciate the greatness of their work we must realise how critical for the whole future of geography was the period in which they lived. It was a period in which great masses of new geographical data were being accumulated, but so long as these remained unsystematised and unrelated, they tended only to increase the inchoate and amorphous character of a subject which was rather a torture to the memory than a stimulus to the mind. It was a period, too, in which many independent, specialised sciences dealing with particular aspects of earth lore such as geology and meteorology were rapidly developing so that the domain left to geography itself, according to the prevailing conception of its character, was increasingly uncertain. It was Ritter and Humboldt who rescued what seemed indeed to be a moribund subject and gave it co. herence, individuality, and an immensely enhanced significance. This they did by claiming for it not a distinctive segment in the circle of knowledgewhich is to destroy its very essence-but a distinctive method and objective in the handling of data common to other subjects. Ritter gave the keynote to the whole modern development of geography when he said (in his "Comparative Geography ") "It is to use the whole circle of sciences to illustrate its own individuality, not to exhibit their peculiarities. It must make them all give a portion, not the whole, and yet must keep itself single and clear." Geography, he maintained, could only escape disintegration "by holding fast to some central principle; and that principle is the relation of all the phenomena and forms of nature to the human race".

The framework which the great pioneers of the early nineteenth century defined for the building up of a geographical synthesis, which in Ritter's view culminated in man's relationship to the earth, was sufficiently wide to permit of many converging contributions. Workers in many fields of geography were henceforth guided by the same fundamental principles and methods, and whether in geomorphology, in climatic or human geography, the central object became to exhibit the earth as a whole made up of related and interacting parts.

It is no doubt true that some of the workers in contributory fields have been initially trained in the special science which supplied the data, that is, have been in the first instance geologists or zoologists, but it is equally remarkable that many of them, when once they have acquired the geographical outlook, have changed their objective and become primarily interested in placing or interweaving their contribution in the geographical syn-

* From the presidential address to Section E (Geography) of the British Association, delivered at Bristol on Sept. 5. thesis as such. For it is from these main sources-geomorphology, climatic and biological (plant and animal) geography -that we derive the data for building up that systematic geography of natural environments which is at once the objective of 'physical' geography and the starting-point of human geography.

The fundamental objectives of geography are the same to-day as those which the Greek philosophers of Asia Minor and Alexandria conceived. There is a ' modern geography' only in the sense that there has been a restatement of its scope and content in the light of all the new knowledge of the earth which more specialised branches of inquiry have revealed. It was the work of the great pioneers of the nineteenth century to disentangle it from these associated subjects and to ascertain the guiding principles through which and the means or technique by which contact and relationship with them could be most fruitful and helpful in the attainment of the ends for which all science stands. This clarification of its scope and methods was essential if geography was to be in a position to seize the opportunities for increased usefulness afforded by the conditions of the modern world. For the two circumstances which, granted vision and understanding on the part of its exponents, have inevitably enhanced the significance and value of our subject are surely these : that on one hand our more complete knowledge of the earth and of the distribution of phenomena over its surface has made it possible to formulate farreaching and valuable generalisations as to their co-ordination and relationship for which the material had hitherto been lacking, and on the other that the rapidly increasing interdependence and inter-sensitiveness of the different regions and peoples of the planet have made a synthetic view of the world as of a whole made up of interrelated parts - which is the prime object of geographyessential to human progress.

It is against this background of modern geography as a whole that the special aims and contributions of that part of it which we call human geography must be considered. The separate, departmental 'political geography' of the early nineteenth century is for ever discredited. Whatever value human geography may have is involved in its association with all the rest of the subject matter. It is on the question of the precise nature of the relationship that difference of view arises.

From the ranks of geographers themselves-as distinct from the views on the influence of natural conditions on human societies put forward from time to time by philosophers and economists such as Feuerbach, Engels, and Marx, or historians such as Buckle and Meyer-the two chief contributions have come from the school of thought associated with the name of Ratzel and that associated with the name of Vidal de la Blache.

No. 3182, VoL. 126] 
'Determinism' and 'possibilism' are the respective labels which have been attached to the two schools, and although labels, hore as elsewhere, are liable to mislead, they sufficiently indicate a fundamentally different emphasis and attitude between the two in their treatment of the relationship of human societies to their natural environments. In the first or Ratzelian School the main emphasis is undoubtedly on the control of human activities by natural conditions, on the limitations which these impose, on the permanency of the stage, "always", as Ratzel insisted, "the same and always situated at the same point in space", and of the influences which it exerts, on the inevitability of particular developments, given a certain milieu. This attitude is even more pronounced in the works of some of the disciples of that other school of French human geographers or, as it is perhaps better to call them, geographical sociologists, who drew their inspiration from Le Play's "Ies ouvriers européens", although Le Play himself cannot be identified with all their views. Geographical 'determinism" reaches its culmination in the "Comment la route crée le type social" of Demolins, who maintains that if history were to begin all over again it must in all essentials follow the same lines, given the same setting of the stage. Apart from the question of bias on the compelling power of physical circumstances, a criticism which has been levelled, as I think rightly, against the Ratzelian School, is that it is excessively dogmatic, and that, notwithstanding the vast amount of material which Ratzel himself and many of his disciples have sifted and classified with great skill, we are far as yet from having the data necessary for many of the big generalisations which they make.

The same criticism can certainly not be brought against Vidal de la Blache and his followers, whose discussions of these issues, while often extremely suggestive and illuminating, are rarely dogmatio or final in their conclusions or implications. The master himself did indeed deal in his larger works with what may justifiably be called "principles" of human geography, but his teaching was always that the larger generalisations could only gradually emerge from a series of detailed and exact regional studies, and we shall all admit, I think, that his disciples have been very true to his precepts. The conception appears in the approach and particularly in the form even of the more ambitious work of Brunhes which bears the title "La géographie humaine". It is scarcely possible in a few sentences to characterise la Blache's concept of human geography, but $\mathrm{I}$ find its dominant note and one which brings it into salient contrast with the Ratzelian Sohool in the following paragraph :

"L'être géographique d'une contrée n'est point une chose donnée d'avance par la nature, une offrande du monde inanimé ; elle est un produit de l'activité de l'homme, conférant l'unité à des materiaux qui, par eux-mêmes, ne l'ont point. . . . Si une contrée est une personne, c'est par l'effort de ceux qui l'habitèrent." The emphasis here and throughout his work is not so much on the determinative influence of the stage per se, although this is always presented as a vital factor, as on the creative power of human groups to adapt themselves to and, within limits, to mould the natural environment, to leave their impress upon it and thus in the course of generations to transform it and give it a personality which is the outcome of the interaction. This personality is not constant. It may change with man's use or abuse of his habitat.

With this indication of some dominant tendencies in the setting and perspective of human geography $I$ pass to an attempt to define more closely its subject-matter and its different aspects. I believe that in essence human geography consists of the study of $(a)$ the adjustment of human groups to their physical environment, including the analysis of their regional experience and of $(b)$ inter-regional relations as conditioned by the several adjustments and geographical orientation of the groups living within the respective regions. The term "adjustment 'I take to cover not only the ' control' which the physical environment exerts on their activitics but also the use which they make or can make of it. Human geography is the study of an interaction rather than of a control. The adjustment has distinet but usually elosely related aspects which form the main branches of human geography. The relationship between them is from the geographer's point of view as intimate as that between the different branches of physical geography. The four principal aspects may be distinguished as the racial, economic, social, and political.

The racial aspect implies an adjustment of a different character from the others, one over which man has had little control but which he can increasingly influence through his better understanding of the issues involved. I am well aware that in touching on racial geography $I$ am treading on dangerous and controversial ground. Yet I am convinced that it is as necessary to find the right relationship between human geography and anthropology as it is between physical geography and geology and that racial geography is as significant and essential a part of the geographical synthesis as is geomorphology. I think it is true to say that racial determinism, that is, the explanation of characteristics in terms of race alone, apart from environmental conditions, is becoming as discredited as geographical determinism, the explanation of everything in terms of physical environment.

The tendency in anthropology is certainly not in the direction of appraising racial types, so far as they can be definitely distinguished, according to an absolute scale of value or efficiency, but relatively to the geographical environments in which they are found. Their somatic traits are discussed in terms of regional adaptations and the fruitful hypothesis is put forward that so far from racial varieties being unchanging and fixed for all time they are continually undergoing slow modification and in process of becoming. Now the unit of the geographer's study is not race as such any more than it is climate as such or any other physical element. His unit is the place or region. It is this concept-and I do not think it can be emphasised too strongly - which gives distinctiveness and 
individuality to his work. With the relationship of climate and other physical factors to race in a region, the geographer is closely concerned and there are few more important aspects of his study than the composition, actual or potential, of the societies occupying the region.

In the world of to-day there are many regions of 'closed' human associations, if I may borrow a useful term from plant geography, regions such as China or the Mediterranean lands as a whole where the dominant racial type or types in possession are so numerous and well adjusted that the entry of any important new racial element is extremely unlikely. But there are other regions of 'open' human associations, at present thinly peopled but capable of holding a much larger population, whose racial future is uncertain. Such, for example, are tropical Australia and parts of Malaya, of Africa, even of Asia. Is it possible or desirable for the geographer in his study of these regions to confine himself to their resources and economic possibilities and not to consider at all, in the light of all that he can learn from anthropology, the relative aptitudes and adaptability, climatic and otherwise, of various racial groups for developing them and the extent and manner in which co-operation between different groups may be secured for this end?

Take, for example, the highly important pronouncement made by (xeneral Smuts last autumn in one of his Rhodes' lectures at Oxford. In tho course of his plea for the advance of native Africa through the introduction of a higher civilisation in the form of white settlement, he advocated "a strong forward movement in the policy of settling the highlands of Eastern Africa which stretch in an unbroken belt, hundreds of miles broad, from Kenya to South Africa". It is not for me to express an a priori opinion on the wisdom of this suggestion, but it raises vitally important issues of human geography.

These issues are at once racial and economic in character. Do we yet know enough about the effects of a high plateau climate in equatorial latitudes on peoples of North European stock? Even if it be granted that satisfactory acclimatisation of such peoples in the Kenya Highlands can be achieved, are the conditions of the plateau belt as a whole intervening between them and' temperate' South Africa sufficiently similar to warrant the prospects of an equally good adjustment? The tentative generalisation has been made that, from the point of view of the success of "white 'planta. tions, there is a vital difference between the $4500 / 6000$ feet altitude of the Kenya Highlands and other smaller mountainous 'islands' to the south and the 3500 feet level which seems to charac. terise most of Tanganyika. Or again, what are the prospects of making the "fly belt' suitable for white settlement? Or, granted favourable climatic and other physical conditions, have the economic relations likely to be established between the proposed white settlers and the native Bantu tribes been sufficiently considered from the point of view of the uses which the two groups are likely to make of the land? It is not cartographical surveys alone-although these are vital and the basis of all others-which need to be made before such questions can be answered.

Similar questions arise concerning the future of southern Brazil, Malaya, parts of central and eastern Asia, and many other regions where groups with different racial characteristics and aptitudes are in competition. The racial aspect is only one of several, but the study of racial distributions, based on anthropological material in the same sense that geomorphology is based on geological material, seems an essential element in the content of human geography. Personally I feel it to be a distinct gain that, in at least one university, geography should be closely associated with anthropology, so long as it is not identified with it, just as in others it is more closely associated with economics or history or with physical science.

It is unnecessary for my present purpose to elaborate what is implied in that aspect of man's adjustment the study of which forms the subjectmatter of economic geography. It is of course a fundamental and basic aspect, including the geography of production (with agricultural and industrial geography as its principal subsections) and the geography of exchange (commercial geography in the more technical sense).

Economic geography serves one of its highest functions if it is closely linked with other aspects of human adjustment to physical environment which have so far received less attention. Of these one of the most interesting and profoundly im. portant is that which for want of a better term we usually call social geography. This may be broadly defined as the analysis of the regional distribution and interrelation of different forms of social organisation arising out of particular modes of life which themselves represent a direct responsealthough we may concede to M. Febvre not necessarily the only possible response--to distinctive types of physical environment. A classical example of the importance of this aspect is of course the age-long conflict between nomadic, patriarchal pastoralists and peasant cultivators, socially organised on a territorial basis, along the grassland borders of the hot deserts in Africa and Arabia and round the edges of the steppe-belt in Euro-Asia.

In modern times the problems connected with the interregional relations of differently organised groups in Africa and elsewhere have been greatly complicated by the impact of industrial Europe on their lives. It has particularly affected the traditional societies of intertropical Africa, the monsoon lands, and the South Sea Islands, where mode of life and social organisation, once established as an adjustment to their milieu, often remained in essentials unchanged until they were so suddenly, and in some cases so tragically, drawn into the maelstrom of modern commerce. In the last analysis this disturbance is one of the chief causes of world-wide unrest, since equilibrium with environment is the first essential of happiness for human groups.

One of the greatest needs of our time is to discover what for each type of regional environment or

No. 3182, VoL. 126] 
milieu are the real factors in readjustment through which alone the recovery of equilibrium can be attained. What is involved is readjustment to all the local conditions of the habitat in the light of its new contact with other regions, its new place in the total scheme of world relationships. Modern Denmark would seem to be an admirable example of a successful readjustment of this kind. Statesmanship in such an Empire as ours is increasingly concerned with the task of harmonising the interests of many groups cradled in different environments, diverse in race, mode of life, and experience, but, under the conditions of the world to-day, increasingly interdependent. Particularly is this apparent in the problem of the readjustment of African societies, one of the most critical and complex of our time and one for the solution of which Great Britain has incurred heavy responsibilities. Such problems are as much geographical in character as those concerned with the regional planning of English districts, and equally demand detailed surveys by investigators capable of analysing the social life and experience of human groups in their whole geographical setting and of appreciating the significance of the new elements in their environment.

The modern tendency in geography to think of the earth in terms of natural as opposed to artificial divisions should not lead to the neglect of political geography in the proper sense of the term; for the function of political geography is to study and appraise the significance of political and administrative units in relation to all the major geographical groupings, whether physical, ethnographic, social, or economic, which affect mankind. It is essentially an aspect of adjustment to geographical environment, and it is precisely because it is so closely related to other aspects of adjustment, which in the influences that they exert are often conflicting, that equilibrium is so difficult to attain. The study of the mode in which geographical conditions have helped to mould the evolution of States in the past is of absorbing interest, however complex and difficult. The existence of favourable areas of characterisation possessing a considerable amount of natural protection, such as the English Plain and the Central Lowlands of Scotland, within which the social contact of orginally different racial and social groups was easy, certainly provided the medium through which in western Europe strong nation-States tended to take shape. The group consciousness which we call nationality seems to have followed rather than preceded the actual formation of such States. Nationality arose in relation to environment and widened its scope and allegiance with the increase of economic and political contact.

Since the forces promoting the contacts and economic interdependence of regions are operating on a much bigger scale in the world of to-day than ever before, we might expect to see this process of political integration even more strongly marked, and the rapid territorial growth of the United States and other large political entities can be quoted as examples of it. But in Europe we see this process arrested and even reversed.
Nationality, as tested by linguistic and cultural affinities, rather than the economic orientation indicated by the physical conditions, has been accepted as the main criterion of the new units, although there is frequent departure from this principle. The new Europe is admittedly a great experiment in political geography. Its success would seem to depend on the possibility of reconciling the different factors. The most stable political units are undoubtedly those which most correspond to geographical realities, but these realities are not wholly limited to considerations of physical and economic geography. The distribution of groups related in culture and language is also a geographical reality. The ideal State from the geographical point of view is one which neither divides groups culturally related nor interferes with the flow of trade along natural arteries and between regions economically interdependent. It may be, although as yet the indications are not very hopeful, that the urgent need of Europe for greater economic integration can be reconciled with the desire of the small nationality groups for cultural and political autonomy. It may be that economic federation or agreement among small sovereign-States within the framework of the League of Nations will prove the only alternative to the 'super-State' solution of the problem of European political geography propounded by Naumann in his "Mittel Furopa". At any rate, nationality, considered apart from its geographical setting, may be a very dangerous conception.

I have tried to indicate the essential character of the principal aspects of human geography, each of them from the point of view of the adjustment of human groups to their geographical environment. It is permissible and desirable to pursue special studies of these various aspects of our subject, but they find their fullest fruition when they are brought together and inter-related in a full and comprehensive treatment of regions. We can never really appreciate the problems of such countries as India, China, and Russia until we have a comprehensive interpretation of their human ecology, to use the expressive term employed by the American geographer Barrows. In the future it is probable that geographical specialism in the universities will be less concerned with aspects (such as geomorphology, climate, and economic geography) -although this will always have its place-and more concerned with regions (the Mediterranean, tropical Africa, the Far East, and so on). The geographer's parish must indeed be the world, but it is too large a parish for all parts of it to be studied in detail by any one man. He must, if he is entrusted with a university department, delegate responsibility for as many regional chapels-of-ease as he can find associates and colleagues to work them.

We may claim for human geography that, rightly studied, it is a vital element in training for national and international citizenship. It can enable us "accurately to imagine the conditions of the great world stage " and the place of the different regions within it. It is a valuable mental discipline, calling

$$
\text { No. 3182, VoL. 126] }
$$


for an exact sense of proportion in appraising the value of many factors and more specifically developing the great quality of sympathetic understanding. The point of view and type of outlook which it fosters were nover more needed than in the present critical stage of human development. Yet not only through its value as an educational instrument, but also through the programme of constructive work which it advocates, can it contribute to the realisation of the ideal of "unity in diversity", and that seems the only possible ideal for the life of humanity on a planet which, however small applied science may make it, will always retain its infinite variety.

\section{Chemical Measurements by Colour.}

\section{By Dr. L. C. Maktin.}

$\mathrm{I}^{\mathrm{T}}$ T. is a pity that the word 'colorimeter' has been applied to two entirely distinct classes of instrument. The name is given most appropriately to those instruments which actually measure colour, albeit in relative terms, and not to those in which the chemical concentration of a solution is the subject of determination. The latter, which form the topic of the present article, are strictly colour comparators, and it would be an advantage if they could so be called. The alternative names chromometer and chromatometer also fail to give the proper indication, but would be preferable to 'colorimeter'.

There are many chemical substances which, although difficult to determine quantitatively in very dilute solutions by chemical methods, have the property of strong selective absorption of light. According to the law of Beer, the absorption coefficient of a solution is directly proportional to the concentration. Since this law holds with fair accuracy for most dilute solutions, it follows that the colour change in transmitted light obtained by varying the concentration (within certain ranges) can be exactly imitated by increasing the thickness of the medium which must be traversed; thus, if $1 \mathrm{~cm}$. of solution $A$ gives the same colour as $10 \mathrm{~cm}$. of solution $B$, we should expect (provided that the above law held) that the amount of material dissolved in unit volume of $A$ is ten times that of $B$. The application of this principle to find the concentration of a solution of unknown strength, given one of the same material and of known strength, is quite clear. Failing a means of using different thickness of solution, the alternative is to prepare a number of samples of known concentration and to endeavour to place the unknown in its relation to the rest-a method much less elegant, but of value when Beer's law is likely to break down. In practice, no such liberties as indicated above in the "ten to one "example are advisable. According to Thorpe, if the strength of the standard differs by more than 10 per cent from that of the test liquid, it is usual to dilute one or the other (in a known ratio) before comparison, so that the lengths to be compared are approximately equal.

It is not possible in a short article to do more than indicate some of the numerous applications of the method. It is used in the estimation of small quantities of the salts of copper, tin, lead, iron, cobalt, manganese, and other metals; also in the determination of dyes and natural colouring materials. Krüss mentions the estimation of salicylic acid in surgical wadding, and the examination of the coloration given by animal charcoal. Other applications are met in the operations of the oil, sugar, and brewing industries. Special instruments with artificial standards are applied in the determination of the sugar content of the blood of diabetic patients. An account of practical methods will be found in Iunge-Berl's "Chemische-technische Untersuchungsmethoden ", vols. 1, 2, 3, and 4, and in books such as "Colorimetric Analysis", by B. Snell.

The early methods of application of the principle were of the simplest description; an account of them is given in 'Thorpe's "Dictionary of Applied Chemistry", vol. 2, p. 340. Flat-ended tubes placed side by side were often employed, sky - light being reflected through their lengths by a mirror. It is well known, how ever, that the exact comparison of separated colour fields is very difficult. Ir 1910 Autenreith and Königsberger ${ }^{1}$ used a colorimeter with a Helmholtz 'Doppel. platte' for approximating the comparison fields. A movable hollow wedge affords the means of varying the thickness of the test solution. This was used for the determination of hæmatin in blood and other medical work. Another early suggestion aiming at better optical accuracy was that of $\mathrm{H}$. Krüss, who suggested the use of the Swan or LummerBrodhun double prism in order to secure a comparison field with an indefinitely narrow separation.

The most practical arrangement was, however, due to Dubosca, ${ }^{3}$ who gave the instrument its most usual modern form, Fig. 1. The rays traversing the vertical cylinders holding the solutions are brought into one field by the use of two rhomb reflectors; or a single symmetrical rhomb can be employed. A lens brings these groups of parallel rays into one focus, where a telecentric stop is placed so as to prevent stray light from reaching the eye. The eye-lens helps bo bring the sharp line of separation into exact visual focus in the field of view. In order to vary the thickness of solution traversed, the vessels containing the solution (shaded in the figure) can each be moved on vertical slides by rack and pinion. Thus the flat-ended cylinders, either closed tubes or glass rods

No. 3182, VoL. 126] 